\title{
SMO Protein Inhibitor ZSP1602
}

National Cancer Institute

\section{Source}

National Cancer Institute. SMO Protein Inhibitor ZSP1602. NCI Thesaurus. Code C159535.

An orally bioavailable small molecule SMO (Smoothened) inhibitor with potential antineoplastic activity. SMO inhibitor BMS-833923 inhibits the sonic hedgehog (SHH) pathway protein $\mathrm{SMO}$, which may result in a suppression of the $\mathrm{SHH}$ signaling pathway. $\mathrm{SMO}$ is a G-protein coupled receptor that lies just downstream of the SHH ligand cell surface receptor Patched-1 in the SHH pathway; in the absence of lig and Patched-1 inhibits SMO and ligand binding to Patched-1 results in increased levels of SMO. The SHH signaling pathway plays an important role in cellular growth, differentiation and repair; constitutive activation of this pathway is associated with uncontrolled cellular proliferation and has been observed in a variety of cancers. 